\title{
DIVERSIDADE E PADRÕES DE DISTRIBUIÇÃO ESPACIAL DE ESPÉCIES NO ESTÁGIO DE REGENERAÇÃO NATURAL EM SÃO FRANCISCO DE PAULA, RS, BRASIL
}

\author{
Maria Raquel Kanieski ${ }^{1}$, Solon Jonas Longhi ${ }^{2}$, Igor da Silva Narvaes ${ }^{3}$, Philipe Ricardo Casemiro Soares ${ }^{4}$ \\ Tomaz Longhi-Santos ${ }^{5}$, Rafael Marian Callegaro ${ }^{6}$
}

${ }^{1}$ Eng ${ }^{\text {a }}$ Florestal, M.Sc., Doutoranda em Engenharia Florestal, UFPR, Curitiba, PR, Brasil - raquelkanieski@ gmail.com
${ }^{2}$ Eng. Florestal, Dr., Depto. de Ciências Florestais, UFSM, RS, Brasil - longhi.solon@ @mail.com
${ }^{3}$ Eng. Florestal, Dr., INPE, Depto. de Sensoriamento Remoto, São José dos Campos, SP, Brasil - igor@ dsr.inpe.br
${ }^{4}$ Eng. Florestal, M.Sc., Depto. de Eng. Florestal, UDESC, Lages, SC, Brasil - prcsoares@ gmail.com
${ }^{5}$ Eng. Florestal, Mestrando em Engenharia Florestal, UFPR, Curitiba, PR, Brasil - tomazlonghi@ gmail.com
${ }^{6}$ Eng. Florestal, Doutorando em Engenharia Florestal, UFSM, Santa Maria, RS, Brasil - mariancallegaro@ @ahoo.com.br

Recebido para publicação: 21/11/2011 - Aceito para publicação: 16/08/2012

\begin{abstract}
Resumo
Objetivou-se com este trabalho a análise da diversidade florística e da distribuição espacial de espécies da regeneração natural em um fragmento de Floresta Ombrófila Mista na Floresta Nacional de São Francisco de Paula (RS), mediante a comparação de diferentes índices de diversidade e dispersão. A amostragem da vegetação foi realizada por meio de 180 subunidades de $10 \mathrm{~m} \mathrm{x} 10 \mathrm{~m}$, onde foram inventariados todos os indivíduos com altura superior a $1,30 \mathrm{~m}$ e com circunferência à altura do peito (CAP) mínima de 3,0 cm, até a circunferência limite de $29,9 \mathrm{~cm}$, considerados como regeneração natural. Foram calculados os parâmetros de frequência e densidade, os índices de dispersão de MacGuinnes, de Fracker e Brischle e de Payandeh e diferentes índices de diversidade alfa. Os índices de dispersão revelaram o mesmo comportamento para as espécies, que se mostraram agregadas ou com tendência ao agrupamento. O índice de Margalef revelou valores subestimados da diversidade, possivelmente influenciado pelo tamanho da unidade amostral. O índice de Menhinick e o índice de Shannon representaram a diversidade de forma bastante real, mesmo em unidades amostrais pequenas. Os índices de Simpson e MacIntosh denotaram baixa dominância, e os índices de equidade demonstraram alta uniformidade nas espécies.

Palavras chave: Floresta Ombrófila Mista; fitossociologia; índices de dispersão; índices alfa.
\end{abstract}

\begin{abstract}
Diversity and patterns of spatial distribution of species of natural regeneration in São Francisco de Paula, RS, Brazil. This work aimed the analysis of floristic diversity and spatial distribution of species of natural regeneration in an area of Mixed Rainy Forest in the National Forest of São Francisco de Paula, RS, comparing different diversity and dispersion indexes. The vegetation sampling was performed by analyzing 180 subunits of $10 \mathrm{~m} \mathrm{x} 10 \mathrm{~m}$, with all the individuals taller than $1.30 \mathrm{~m}$ and with breast height circumference from $3.0 \mathrm{~cm}$ to the limit of $29.9 \mathrm{~cm}$, considered as natural regeneration. The parameters of frequency and density, dispersion indexes of MacGuinnes, Fracker and Brischle and Payandeh, and different alpha indexes of diversity were calculated. The dispersion indexes revealed the same behavior for the species, which are aggregated or presented a tendency to cluster. Margalef index was underestimated, possibly influenced by the size of sample unit. The Menhinick and Shannon indexes represented the diversity in a very real form, even in small sampling units. The indexes of Simpson and MacIntosh denoted low dominance and the equity indexes revealed high uniformity in species.
\end{abstract}

Keywords: Mixed Rainy Forest; phytosociology; dispersion indexes; alpha indexes.

\section{INTRODUÇÃO}

A cobertura florestal nativa no Brasil sofre um processo de destruição contínuo, por meio da retirada de madeira, de queimadas e da expansão de fronteiras agrícolas, entre outros fatores, o que caracteriza extremo descaso com os recursos naturais ainda existentes. No Brasil, a área original de 
Floresta Ombrófila Mista era de aproximadamente $200.000 \mathrm{~km}^{2}$. Hoje, estima-se que seus remanescentes, nos estágios primários ou mesmo avançados, não perfazem mais de 0,7\% da área original (BRASIL, 2002), o que a coloca entre as tipologias mais ameaçadas. Em virtude disso, estudos se tornam cada vez mais importantes para subsidiar o estabelecimento de planos de conservação que sejam eficientes para esses ecossistemas.

O conhecimento da vegetação é necessário para inúmeras atividades de investigação e desenvolvimento, por sua importância no sistema ecológico, captadora e transformadora da energia solar, porta de entrada da energia e da matéria na cadeia trófica, armazenadora de energia, provedora de refúgio para a fauna, agente antierosivo do solo, regulador do clima local, redutor da contaminação atmosférica e do ruído e fonte de matéria-prima para o homem (MATTEUCCI; COLMA, 1982).

Analisar a regeneração natural de um fragmento florestal permite uma investigação efetiva para diagnosticar o estado de conservação deste. Além disso, seus processos regenerativos são importantes para o sucesso de seu manejo, o qual necessita de informações básicas em qualquer nível de investigação (DANIEL; JANKAUSKIS, 1989; AMADOR; VIANA, 2000).

O estudo de padrões de distribuição espacial é hoje uma das ferramentas mais utilizadas para se entender o comportamento de diversos fenômenos (ANJOS et al., 1998). Segundo Barros e Machado (1984), o conhecimento do padrão espacial das espécies pode fornecer informações sobre a ecologia, subsidiar a definição de estratégias de manejo e conservação, além de auxiliar em processos de amostragem e esclarecer a estrutura espacial de uma espécie.

A diversidade biológica é um tema central da teoria ecológica e tem sido objeto de amplo debate. Atualmente se tem desenvolvido uma grande quantidade de parâmetros para a medição da biodiversidade como um indicador do estado dos sistemas ecológicos, com aplicabilidade prática para fins de conservação, manejo e monitoramento ambiental (MAGURRAN, 1988).

A hipótese deste trabalho sugere que os índices de diversidade e dispersão são bons padrões para caracterizar a atual situação de conservação da área e, ainda, que eles mostrarão resultados diferentes, de acordo com a peculiaridade de cada índice, apresentando distintos padrões de diversidade e espacialização das espécies na área.

Diante do que foi mencionado, objetivou-se, com este trabalho, a determinação e análise da diversidade florística e da distribuição espacial de espécies em estágio de regeneração natural, mediante a comparação de diferentes índices, em área de Floresta Ombrófila Mista na Floresta Nacional de São Francisco de Paula (RS).

\section{MATERIAL E MÉTODOS}

\section{Caracterização da área de estudo}

A Floresta Nacional (FLONA) de São Francisco de Paula está localizada no nordeste do Rio Grande do Sul, na região dos Campos de Cima da Serra, na cidade de São Francisco de Paula, na Serra Gaúcha. Possui uma área total de 1.606,69 ha, dos quais 901,9 ha são ocupados por florestas nativas (Floresta Ombrófila Mista e Densa), mais de 600 ha por florestas plantadas e o restante por outras áreas, como, campos, lagos e de infraestrutura, entre outros.

A exploração dos recursos florestais na FLONA tem como prioridade a utilização dos recursos madeiráveis, principalmente Pinus sp., e também recursos não madeiráveis, como a coleta do pinhão. A unidade também conta com o uso turístico, educacional e de pesquisa (SILVEIRA, 2006).

A região é uma das áreas de maior intensidade pluviométrica do estado, com pluviosidade superior a $2.000 \mathrm{~mm}$ por ano e temperatura média anual de aproximadamente $14,5^{\circ} \mathrm{C}$. De acordo com a classificação climática de Köppen, o clima é do tipo "Cfb", mesotérmico médio (MORENO, 1961). Os solos encontrados na FLONA são dos tipos Cambissolo Húmico Alumínico, Chernossolo Argilúvico Férrico e Neossolo Litólico Eutrófico (EMPRESA BRASILEIRA DE PESQUISA AGROPECUÁRIA (EMBRAPA), 1999). Segundo Ribeiro et al. (2007), a área da FLONA é marcada por relevo ondulado a fortemente ondulado na parte norte, com altitude de $930 \mathrm{~m}$, e acidentado na parte sul.

A vegetação florestal predominante pertence à Floresta Ombrófila Mista, mata de araucária ou floresta de pinheiro-brasileiro. Além da Araucaria angustifolia (Bertol.) Kuntze, que imprime um caráter fisionômico nessa vegetação, é comum encontrar outras espécies arbóreas em estágio de regeneração natural características desse tipo fitogeográfico, como Sebastiania commersoniana (Baill.) L. B. Sm. \& 
Downs (branquilho), Cedrela fissilis Vell. (cedro) e Podocarpus lambertii Klotzsch ex Endl. (pinheirobravo), entre outras (NARVAES et al., 2005).

\section{Amostragem}

O trabalho foi realizado nas parcelas permanentes do Projeto Ecológico de Longa Duração (PELD/CNPQ) na FLONA de São Francisco de Paula. As unidades amostrais consistem em 10 conglomerados permanentes de $100 \mathrm{~m} \times 100 \mathrm{~m}\left(10.000 \mathrm{~m}^{2}\right)$, os quais foram divididos em 10 faixas de $10 \mathrm{~m} \times 100 \mathrm{~m}(1.000$ $\mathrm{m}^{2}$ ), e estas subdivididas em 10 subunidades de $10 \mathrm{~m} \times 10 \mathrm{~m}\left(100 \mathrm{~m}^{2}\right)$, obedecendo ao procedimento amostral utilizado no inventário florestal contínuo do Rio Grande do Sul (RIO GRANDE DO SUL, 2002).

Para este trabalho, das 10 unidades amostrais de $100 \mathrm{~m} \times 100 \mathrm{~m}$, onde se realizou o inventário por censo no PELD/CNPQ, foram selecionadas seis unidades distantes entre si, com o objetivo de identificar locais com características ambientais distintas. Dentro de cada unidade amostral selecionada, ainda foram sorteadas 30 subunidades de $10 \mathrm{~m} \mathrm{x} 10 \mathrm{~m}$, onde foram feitos os levantamentos da regeneração natural, totalizando 180 unidades amostrais.

\section{Coleta de dados}

Foram considerados todos os indivíduos da regeneração natural com altura superior a 1,30 m e com circunferência à altura do peito (CAP) mínima de $3,0 \mathrm{~cm}$, até a circunferência limite de $29,9 \mathrm{~cm}$. Os indivíduos amostrados foram numerados e identificados botanicamente. A identificação, em nível de família, gênero e espécie, foi obtida por meio de consulta ao Herbário do Departamento de Ciências Florestais (HDCF), seguindo o Sistema de Classificação APG II (ANGIOSPERM PHYLOGENY GROUP II (APG II), 2003).

\section{Caracterização florística}

Foram calculados os parâmetros fitossociológicos de densidade e frequência, citados por diversos autores (MATTEUCCI; COLMA, 1982; DURIGAN, 2003; FELFILI; REZENDE, 2003), calculados por meio do aplicativo computacional Mata Nativa 2, desenvolvido por Consultoria e Desenvolvimento de Sistemas Ltda. (CIENTEC) (2008).

Tabela 1. Índices de diversidade alfa utilizados na avaliação dos dados da amostragem.

Table 1. Alpha diversity indices used in evaluation of sampling data.

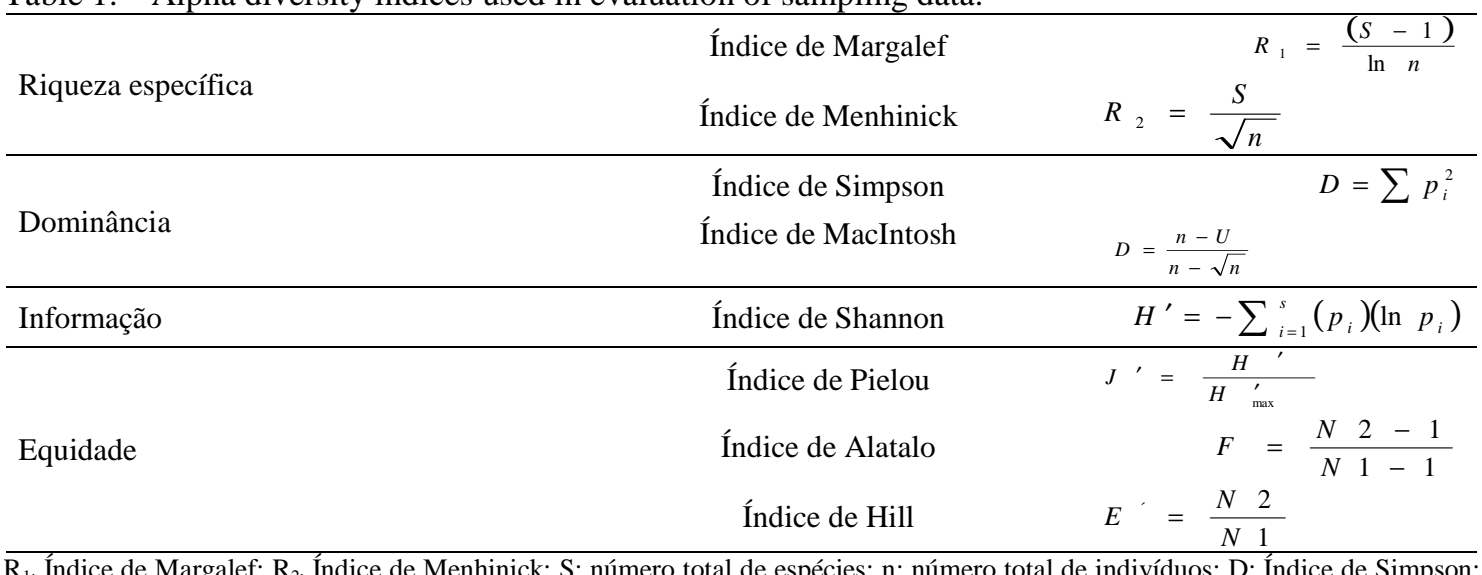

$\mathrm{R}_{1:}$ Índice de Margalef; $\mathrm{R}_{2}$ I Índice de Menhinick; $\mathrm{S}$ : número total de espécies; $\mathrm{n}$ : número total de indivíduos; $\mathrm{D}$ : Índice de Simpson; $\mathrm{p}_{\mathrm{i}}$ : proporção de espécies numa comunidade (PI: ni/n); d: Índice de MacIntosh; $U=\sqrt{\sum n_{i}^{2}}(\mathrm{i}=1,2,3, \ldots, \mathrm{S}) ; \mathrm{H}^{\prime}=$ Índice de Shannon; J': Índice de Pielou; $\mathrm{H}_{\max }^{\prime}$ : $\ln (\mathrm{S})$; F: Índice de Alatalo; N1: número de espécies abundantes: $\mathrm{e}^{\mathrm{H}}$; N2: número de espécies muito abundantes: 1/D; E: Índice de Hill.

Para avaliar o padrão de distribuição espacial das espécies dentro da área de estudo, foram utilizados os índices de dispersão de MacGuinnes, de Fracker e Brischle e de Payandeh, citados por Barros e Machado (1984) e de Payandeh (1970), também calculados por meio do aplicativo computacional Mata Nativa 2. 
Os índices de biodiversidade (Tabela 1) foram apresentados por Krebs (1989), Waite (2000) e Moreno (2001). Eles foram calculados para cada unidade amostral (10 m x $10 \mathrm{~m})$ alocada na área de estudo, por meio do aplicativo computacional Microsoft Excel 2003.

\section{RESULTADOS E DISCUSSÃO}

\section{Caracterização florística}

Foram encontradas 69 espécies, distribuídas em 52 gêneros e 31 famílias, totalizando 7.501,11 indivíduos por hectare. São poucos os estudos de regeneração natural encontrados na FLONA de São Francisco de Paula, sendo que Narvaes et al. (2005) encontraram valores na composição florística maiores do que os encontrados neste estudo, com 109 espécies diferentes, distribuídas em 88 gêneros e 46 famílias. Essa diferença pode ser explicada pelo fato de os autores citados anteriormente terem contado no inventário os indivíduos mortos, além de outras formas de vida, como cipós, trepadeiras e ervas.

Levando em consideração o número de espécies, as famílias mais representativas foram Myrtaceae, com 18 espécies distribuídas em 10 gêneros, e Lauraceae, com 7 espécies pertencentes a 4 gêneros, além de famílias como Aquifoliaceae (4 espécies e 1 gênero), Fabaceae (4 espécies e 4 gêneros) e Sapindaceae ( 4 espécies e 3 gêneros). Resultados parecidos também foram encontrados por Narvaes $e t$ al. (2005; 2008), sendo as famílias mais representativas Myrtaceae, Solanaceae, Lauraceae, Asteraceae, Euphorbiaceae, Salicaceae e Rutaceae.

As espécies de maior densidade (Tabela 2) foram: Stillingia oppositifolia, com densidade absoluta de 1.455,56 ind.ha ${ }^{-1}$ e densidade relativa de 19,4\%; Casearia decandra (1.093,33 ind.ha" ${ }^{-1}$ e 14,58\%), Sebastiania brasiliensis (847,78 ind.ha $^{-1}$ e 11,3\%), Rudgea parquioides (486,11 ind.ha ${ }^{-1}$ e 6,48\%) e Matayba elaeagnoides (272,78 ind.ha $^{-1}$ e 3,64\%). Resultados muito semelhantes foram encontrados por Narvaes et al. (2005), pelos quais Stillingia oppositifolia, com densidade absoluta de $1.456,11$ ind.ha $^{-1}$ e relativa de 18,24\%, Casearia decandra (1.107,22 ind.ha- ${ }^{-1}$ e 13,87\%), Sebastiania brasiliensis (851,67 ind.ha $^{-1}$ e 10,76\%), Rudgea parquioides (489,44 ind.ha $^{-1}$ e 6,13\%) e Matayba elaeagnoides (272,78 ind.ha ${ }^{-1}$ e $\left.3,42 \%\right)$ foram, assim como no presente estudo, as espécies com maior densidade na área estudada.

Tabela 2. Densidade e frequência das espécies mais abundantes na área amostrada da FLONA de São Francisco de Paula, RS.

Table 2. Density and frequency of most abundant species in the sampled area of the National Forest of São Francisco de Paula, RS.

\begin{tabular}{lccccc}
\hline Nome científico & Nome vulgar & DAi & DRi & FAi & FRi \\
\hline Stillingia oppositifolia Baill. ex Müll. Arg. & Leiterinho & $1.455,56$ & 19,40 & 56,67 & 3,29 \\
Casearia decandra Jacq. & Guaçatunga & $1.093,33$ & 14,58 & 90,56 & 5,25 \\
Sebastiania brasiliensis Spreng. & Branquilho-leiteiro & 847,78 & 11,30 & 61,11 & 3,54 \\
Rudgea parquioides (Cham.) Müll. Arg. & Jasmim-do-mato & 486,11 & 6,48 & 57,22 & 3,32 \\
Matayba elaeagnoides Radlk. & Camboatá-branco & 272,78 & 3,64 & 56,11 & 3,25 \\
Myrceugenia oxysepala (Burret) D. Legrand & Guamirim & 240,00 & 3,20 & 56,67 & 3,29 \\
et Kausel & Guamirim & 206,11 & 2,75 & 52,22 & 3,03 \\
Myrceugenia cucullata D. Legrand & Capororocão & 197,78 & 2,64 & 58,89 & 3,42 \\
Myrsine umbellata Mart. & Guamirim-de-facho & 181,11 & 2,41 & 52,78 & 3,06 \\
Calyptranthes concinna DC. & Guamirim & 137,22 & 1,83 & 43,33 & 2,51 \\
Myrceugenia myrcioides (Cambess.) O. Berg & $\ldots$ & $\ldots$ & $\ldots$ & $\ldots$ & $\ldots$ \\
... & Guamirim & 5,56 & 0,07 & 3,89 & 0,23 \\
Acacia sp. & & $7.501,11$ & 100 & $1.723,89$ & 100 \\
\hline Total & &
\end{tabular}

DAi: densidade absoluta; DRi: densidade relativa; FAi: frequência absoluta; FRi: frequência relativa.

Sebastiania brasiliensis e Stillingia oppositifolia são espécies adaptadas a ambientes úmidos, conforme descrito por Backes e Nardino (1998), enquanto Casearia decandra é uma espécie que se adapta a diferentes habitats, sendo descrita por Marchiori (1997) como árvore pequena que habita, 
sobretudo, o estrato médio da Floresta Ombrófila Mista, explicando sua alta densidade e frequência neste estudo.

A espécie com maior frequência (Tabela 2) nas parcelas amostradas foi Casearia decandra, com $90,56 \%$ de frequência absoluta e 5,25\% de frequência relativa, seguida pelas espécies Sebastiania brasiliensis (61,11\% e 3,54\%); Myrsine umbellata (58,89\% e 3,42\%); Rudgea parquioides $(57,22 \%$ e 3,32\%), Mirceugenia oxysepala (56,67\% e 3,29\%) e Stillingia oppositifolia (56,67\% e 3,29\%). Resultados semelhantes foram encontrados na FLONA de São Francisco de Paula por Narvaes et al. (2005), sendo as espécies de maior frequência absoluta e relativa Casearia decandra (93,33\% e 4,78\%), Sebastiania brasiliensis (61,67\% e 3,16\%), Myrsine umbellata (60,56\% e 3,51\%), Rudgea parquioides (58,33\% e 2,99\%) e Myrceugenia oxysepala $(57,78 \%$ e 2,96\%).

Caldato et al. (1996) encontraram, como espécies de maior frequência e densidade em uma área de Floresta Ombrófila Mista na Reserva Genética Florestal de Caçador (SC), Cupania vernalis, Casearia decandra, Allophylus edulis, Campomanesia xanthocarpa, Myrcia sp., Ilex paraguariensis e Lonchocarpus sp. Segundo os autores, essas espécies são as que apresentam uma sequência mais regular nas fases de crescimento e, portanto, têm maiores possibilidades de sobrevivência na estrutura futura da floresta.

Nota-se, na regeneração, uma baixa densidade e frequência de Araucaria angustifolia, espécie característica desse bioma, o que pode ser explicado pelo fato de a FLONA se tratar de uma unidade de conservação de uso sustentável, ou seja, a coleta e consumo do pinhão, semente de araucária, faz parte da economia e cultura da população, que se beneficia da atividade de extração na Floresta Nacional de São Francisco de Paula, impedindo, dessa forma, a germinação e formação de uma densa regeneração natural nessas áreas. Segundo Caldato et al. (1996), que também encontrou baixos valores da araucária na regeneração, esse comportamento da araucária e de espécies no estágio sucessional inicial é normal, pois as mesmas têm maiores exigências quanto à luminosidade na fase inicial e, portanto, necessitam de perturbações nas florestas, como, por exemplo, a abertura de uma clareira, para crescerem.

Resultados semelhantes também foram encontrados por Narvaes et al. (2005; 2008), os quais sugerem implementação de tratamentos silviculturais e plantios de enriquecimento que beneficiem o seu desenvolvimento, por se tratar da espécie de maior interesse comercial do tipo florestal.

\section{Índices de dispersão}

Os índices de dispersão (Tabela 3) apresentaram padrão semelhante para as espécies estudadas. Para todos os índices, as espécies foram classificadas como agregadas ou com tendência ao agrupamento. Matteucci e Colma (1982) afirmam que as espécies tendem a ter um comportamento agregado no estabelecimento das populações, tendendo a um comportamento uniforme e aleatório no decorrer do processo de sucessão.

Tabela 3. Índices de dispersão das espécies da área amostrada na FLONA de São Francisco de Paula, RS. Table 3. Dispersion indices of species in the sampled area of the National Forest of São Francisco de Paula, RS.

\begin{tabular}{lcc}
\hline MacGuinnes & Fracker e Brischle & Payandeh \\
\hline 65,22\% tendência ao agrupamento, & $85,51 \%$ agregadas, 14,49\% & $79,71 \%$ agrupadas, 20,29\% \\
$34,78 \%$ agregadas & tendência ao agrupamento & tendência ao agrupamento \\
\hline
\end{tabular}

As espécies de maior densidade e frequência, Stillingia oppositifolia, Casearia decandra, Sebastiania brasiliensis, Rudgea parquioides, Matayba elaeagnoides, Myrceugenia oxysepala, Myrceugenia cucullata, Myrsine umbellata, Calyptranthes concinna e Myrceugenia myrcioides, apresentaram todas padrão agregado. Isso mostra que essas espécies de maior densidade e frequência se distribuem na área de forma agregada.

Segundo Vale et al. (2009), o padrão de distribuição agregado evidencia a heterogeneidade do ambiente quando há diferenças na distribuição dos sítios mais favoráveis para o estabelecimento dos indivíduos, ou por ser resultado do tipo de dispersão de sementes ou mesmo pela ocorrência da propagação vegetativa. 
Como causas de agregação dos indivíduos, podem-se citar alguns fatores que ocorrem de maneira diferenciada no interior da floresta, como temperatura, umidade, disponibilidade de luz, topografia, fertilidade do solo etc. (GAMA et al., 2002).

Como citado por Yared (1996), o padrão de distribuição é afetado pela dispersão de sementes, que, por sua vez, é bastante dependente da fauna e da ocorrência de ventos. Estudos futuros combinando espécies zoocóricas seriam interessantes para avaliar a influência da dispersão de sementes no padrão de distribuição da regeneração.

Hutchings (1997) ainda afirma que as sementes caem agrupadas da planta-mãe e requerem microssítios de germinação adequados ao seu estado fisiológico. Assim, as plântulas apresentam quase sempre um padrão de distribuição agregado, o que justifica os resultados encontrados para a distribuição da regeneração no presente estudo.

É possível que a agregação dos indivíduos de grande parte das espécies na área estudada esteja relacionada com a interferência antrópica no ambiente, possível baixa frequência de dispersores e condições edafoclimáticas diferenciadas, entre outros fatores.

\section{Índices de diversidade}

Os índices de diversidade calculados no trabalho (Tabela 4) incluíram os índices de Margalef e Menhinick (riqueza específica), Simpson e MacIntosh (dominância), Shannon (informação) e Pielou, Alatalo e Hill (equidade).

Tabela 4. Índices de diversidade Alfa e Beta para as áreas amostradas na FLONA de São Francisco de Paula, RS.

Table 4. Alpha and Beta diversity indices for the sampled areas in the National Forest of São Francisco de Paula, RS.

\begin{tabular}{lcc}
\hline Índices de diversidade & Valores \\
\hline \multirow{2}{*}{ Riqueza específica } & Índice de Margalef & 3,81 \\
& Índice de Menhinick & 2,05 \\
\hline \multirow{2}{*}{ Dominância } & Índice de Simpson & 0,21 \\
& Índice de MacIntosh & 0,64 \\
\hline Informação & Índice de Shannon & 2,13 \\
\hline \multirow{2}{*}{ Equidade } & Índice de Pielou & 0,76 \\
& Índice de Alatalo & 0,65 \\
& Índice de Hill & 0,71 \\
\hline
\end{tabular}

Os índices de Margalef e de Menhinick seguiram a mesma tendência de valores. Por serem índices que expressam somente a riqueza de espécies, os resultados consideram apenas o número de espécies e indivíduos, variando apenas com o tamanho da área (MORENO, 2001).

Margalef (1956) propôs o Índice de Margalef, que demonstra a riqueza específica e refere-se ao número total de indivíduos. É utilizado para estimar a diversidade com base na distribuição numérica dos indivíduos das diferentes espécies. Quanto maior o valor do índice, maior é a diversidade da comunidade amostrada. O valor encontrado $(3,81)$ caracteriza baixa diversidade quando comparada a um estudo de regeneração natural de Floresta Ombrófila Mista na FLONA de Irati, no Paraná. Nesse estudo, Saueressig et al. (2005) encontraram um valor de 10,68 de diversidade florística no índice de Margalef em parcelas de $10 \mathrm{~m}$ x $50 \mathrm{~m}$, denotando alta diversidade florística. O baixo valor do índice no presente estudo pode ser explicado pelo fato de o índice não levar em consideração a área da parcela amostrada, que, neste caso, é menor que a do trabalho comparado.

De forma semelhante ao Índice de Margalef, o Índice de Menhinick, desenvolvido por Menhinick (1964), baseia-se na relação entre o número de espécies e o número total de indivíduos observados, que aumenta de acordo com o tamanho da parcela. O índice de Menhinick apresentou um valor de 2,05. Assim como o índice de Margalef, fica difícil a caracterização do valor encontrado, por não se considerar a área amostral avaliada.

Os índices de dominância expressam se há dominância por uma ou poucas espécies na área amostrada. O índice de Simpson varia de 0 a 1 , sendo que, quanto mais próximo de 1 , maior a 
dominância. Ao contrário, o índice de MacIntosh vai apresentar maior dominância quando seus valores forem mais próximos de zero. Na dominância de espécies, os dois índices, Simpson e MacIntosh, denotaram baixa dominância por uma ou poucas espécies nas parcelas com valores de 0,21 e 0,64, respectivamente. Os resultados mostram que não há uma ou poucas espécies dominantes nas parcelas amostradas, e sim que o número de indivíduos está bem distribuído entre as diferentes espécies.

É comum encontrar interpretações erradas no índice de Simpson, em que os autores utilizam esse índice como parâmetro de informação da diversidade do local, quando na verdade ele expressa apenas se há ou não dominância de algumas espécies na parcela. Sousa et al. (2008) e Watzlawick et al. (2005) encontraram valores de 0,15 e 0,04 , respectivamente, para o índice de Simpson em áreas de Floresta Ombrófila Mista, e interpretaram como áreas de média e baixa diversidade, quando na verdade esses valores indicam apenas que há baixa dominância de uma ou poucas espécies na área, ou seja, há aproximadamente o mesmo número de espécies distribuídas em cada unidade amostral.

Os índices mais usados são aqueles baseados na teoria da informação. Esses índices expressam diretamente o valor da diversidade, sendo que o mais utilizado é o índice de Shannon. Esse índice obteve uma média de 2,13. Valores semelhantes foram encontrados por Narvaes et al. (2005), utilizando o mesmo tamanho das unidades amostrais na FLONA de São Francisco de Paula, com um valor pelo índice de Shannon de 2,22. Segundo Durigan (1999), os valores desse índice em geral situam-se entre 1,50 e 3,50 para Floresta Ombrófila Mista.

Devido à alta densidade de indivíduos que ocorrem na regeneração natural, e por eles estarem fortemente agrupados, o índice de Shannon acaba tendo boa representatividade da diversidade da regeneração natural mesmo em unidades amostrais menores.

Os índices de equidade mostram de que forma o número de indivíduos está distribuído entre as espécies, denotando menor ou maior uniformidade na composição das parcelas. Os valores nesses índices podem variar de 0 a 1 , sendo que, quanto mais próximo de 1 , maior a uniformidade do local. Para a área em questão, os três índices utilizados, Pielou, Alatalo e Hill, demonstraram a mesma tendência em cada subparcela avaliada, por meio dos valores médios de $0,76,0,65$ e 0,71 , respectivamente, o que denota alta uniformidade na composição das espécies nas parcelas. Esses valores corroboram o encontrado pelos índices de dominância, pois não houve dominância de uma ou poucas espécies, representando alta uniformidade.

\section{CONCLUSÕES}

- Os três índices de dispersão revelaram a mesma tendência, variando apenas com as classificações de cada índice, mostrando que eles são adequados para avaliar a dispersão das espécies em Floresta Ombrófila Mista, segundo a metodologia adotada. Esses índices denotaram comportamento agregado ou com tendência ao agrupamento das espécies, o que é comum para espécies na fase de regeneração natural.

- Os índices de riqueza específica não são adequados para avaliar a diversidade para a área estudada, por não levarem em consideração a área de estudo, o que dificulta a explicação dos resultados.

- Os índices de dominância caracterizaram as parcelas com baixa dominância por uma ou poucas espécies, mostrando que as espécies estão bem distribuídas ao longo das unidades amostradas, o que foi confirmado também pelos índices de equidade, que mostraram alta uniformidade na composição das parcelas.

- O índice de Shannon apresentou valores dentro do esperado para Floresta Ombrófila Mista, representando de forma coerente a diversidade do local, mostrando-se então adequado para a avaliação da informação da diversidade nesses locais.

- Sugere-se intervenções na estrutura da floresta, como abertura de clareiras e o controle da exploração do pinhão, favorecendo o desenvolvimento de espécies importantes na regeneração natural, principalmente a Araucaria angustifolia.

\section{AGRADECIMENTOS}

Ao CNPQ e à CAPES, pela concessão da bolsa de estudos, e ao PELD/CNPQ, pela infraestrutura e suporte durante a realização deste trabalho. 


\section{REFERÊNCIAS}

AMADOR, D. B.; VIANA, V. M. Dinâmica de "capoeiras baixas" na restauração de um fragmento florestal. Scientia Forestalis, v. 57, p. 69 - 85, 2000.

ANGIOSPERM PHYLOGENY GROUP (APG II). An update of the Angiosperm Phylogeny Group classification for the orders and families of flowering plants: APG II. Botanical Journal of the Linnean Society, v. 141, p. 399 - 436, 2003.

ANJOS, A.; COUTO, H. T. Z.; REIS, A. Análise do efeito de um manejo em regime de rendimento sustentável sobre o padrão de distribuição espacial do palmiteiro (Euterpe edulis Martius), utilizando a função K de Ripley. Revista Árvore, v. 22, n. 2, p. 215 - 225, 1998.

BACKES, A.; NARDINO, M. Árvores, arbustos e algumas lianas nativas no Rio Grande do Sul. São Leopoldo: UNISINOS, 1998. 202 p.

BARROS, P. L. C.; MACHADO, S. A. Aplicação de índices de dispersão em espécies de florestas tropicais da Amazônia brasileira. Curitiba: FUFEP, 1984. 44 p. (Série Científica I).

BRASIL. Ministério do Meio Ambiente. Proposta do grupo de trabalho preservação e recuperação da Floresta Ombrófila Mista no Estado de Santa Catarina: Portaria Ministerial 49, de 06 de fevereiro de 2002. Brasília, 2002. 77 p.

CALDATO, S. L.; FLOSS, P. A.; DA CROCE, D. M.; LONGHI, S. J. Estudo da regeneração natural, banco de sementes e chuva de sementes na Reserva Genética Florestal de Caçador, SC. Ciência Florestal, v. 6, n. 1, p. 27 - 38, 1996.

CONSUlTORIA E DESENVOLVIMENTO DE SISTEMAS LTDA. (CIENTEC). Mata nativa 2: sistema de análise fitossociológica e elaboração de inventários e planos de manejo de florestas nativas. Viçosa, MG: CIENTEC, 2008.

DANIEL, O.; JANKAUSKIS, J. Avaliação de metodologia para o estudo do estoque de sementes do solo. Série IPEF, v. 41/42, p. 18 - 26, 1989.

DURIGAN, M. E. Florística, dinâmica e análise proteica de uma Floresta Ombrófila Mista em São João do Triunfo - PR. 125f. Dissertação (Mestrado em Engenharia Florestal) - Universidade Federal do Paraná, UFPR, Curitiba, 1999.

DURIGAN, G. Métodos em análise de vegetação arbórea. In: CULLEN, L.; RUDRAN, R.; VALLADARES-PAUDUA, C. (eds.). Métodos de estudo em biologia da conservação e manejo da vida silvestre. Curitiba, PR: IPÊ/Fundação Boticário/UFPR, p. 455 - 479, 2003.

EMPRESA BRASILEIRA DE PESQUISA AGROPECUÁRIA (EMBRAPA). Sistema brasileiro de classificação de solos. Brasília: EMBRAPA, 1999. 412 p.

FELFILI, J. M.; REZENDE, R. P. Conceitos e métodos em fitossociologia. Brasília: UNB, 2003. 68 p.

GAMA, J. R. V.; BOTELHO, S. A.; BENTES-GAMA, M. de M. Composição florística e estrutura da regeneração natural de floresta secundária de várzea baixa no estuário amazônico. Revista Árvore, v. 26, n. 5 , p. 559 - 566, 2002.

HUTCHINGS, M. J. The structure of plant population. In: CRAWLEY, M. J. Plant Ecology. 2. ed. GrãBretanha: Blackwell Scientific Publication, 1997. p. 325 - 359.

KREBS, C. J. Ecological methodology. New York: Harper Collins Publications, 1989. 654 p.

MAGURRAN, A. E. Ecological diversity and its measurements. New Jersey: Princeton University Press, 1988. 179 p.

MARCHIORI, J. N. C. Dendrologia das angiospermas: das magnoliáceas às flacourtiáceas. Santa Maria, RS: Ed. UFSM, 1997. 271 p. 
MATTEUCCI, S. D.; COLMA, A. Metodología para el estudio de la vegetación. Washington: Secretaría General de la Organización de los Estados Americanos: Programa Regional de Desarrolo Científico y Tecnológico, 1982. 168 p.

MORENO, C. E. Métodos para medir la biodiversidad. Zaragoza: M \& T manuales y tesis SEA, 2001. v. $1,84 \mathrm{p}$.

MOREnO, J. A. Clima do Rio Grande do Sul. Porto Alegre, RS: Secretaria da Agricultura, 1961. 42 p.

NARVAES, I. da S.; BRENA, D. A.; LONGHI, S. J. Estrutura da regeneração natural em Floresta Ombrófila na Floresta Nacional de São Francisco de Paula, RS. Ciência Florestal, Santa Maria, RS, v. 15, n. 4, p. $331-342,2005$.

NARVAES, I. da S.; LONGHI, S. J.; BRENA, D. A. Florística e classificação da regeneração natural em Floresta Ombrófila Mista na Floresta Nacional de São Francisco de Paula, RS. Ciência Florestal, Santa Maria, RS, v. 18, n. 2, p. 233 - 245, 2008.

PAYANDEH, B. Comparison of method for assessing spatial distribution of trees. Forest Science, Bethesda, v. 16, p. 312 - 317, 1970.

RIBEIRO, S. B.; LONGHI, S. J.; BRENA, D. A.; NASCIMENTO, A. R. T. Diversidade e classificação da comunidade arbórea da Floresta Ombrófila Mista da Flona de São Francisco de Paula, RS. Ciência Florestal, Santa Maria, RS, v. 17, n. 2, p. 101 - 108, 2007.

RIO GRANDE DO SUL. Governo do Estado. Secretaria Estadual do Meio Ambiente. Inventário florestal contínuo do Rio Grande do Sul. Porto Alegre, RS: SEMA, 2002.

SAUERESSIG, D.; MORAES, C. M. de; WALK, F.; INOUE, M. T.; FIGUEIREDO FILHO, A. Estudo da similaridade na composição florística entre uma área de Floresta Ombrófila Mista e a regeneração natural em um plantio adulto de pinheiro-brasileiro, na FLONA de Irati. In: ENCONTRO ANUAL DE INICIAÇÃO CIENTÍFICA, 14., 2005, Guarapuava, PR. Anais... Guarapuava, PR: [s.n.], 2005. 697 p.

SILVEIRA, C. F. B. da. A relação entre a Floresta Nacional de São Francisco de Paula e sua população associada: uma perspectiva polissêmica. 113 f. Dissertação (Mestrado em Ecologia) Universidade Federal do Rio Grande do Sul, Porto Alegre, 2006.

SOUSA, S. G. A. de; CARVALHO, J.; BARDDAL, M. L. Diversidade e estrutura fitossociológica de uma floresta ciliar do rio Iraizinho, Piraquara, PR. Disponível em: <http://www.cemac-ufla.com.br/ AnaisTrabVoluntarios4.htm>. Acesso em 18/08/2011.

VALE, V. S. do; CRESPILHO, R. F.; SCHIAVINI, I. Análise da regeneração natural em uma comunidade vegetal do cerrado no Parque Victório Siquierolli, Uberlândia, MG. Bioscience Journal, Uberlândia, MG, v. 25, n. 1, p. 131 - 145, 2009.

WAITE, S. Statistical ecology in practise: a guide to analysing environmental and ecological field data. London: Prentice Hall, 2000. 414 p.

WATZLAWICK, L. F.; SANQUETTA, C. R.; VALÉRIO, A. F.; SILVESTRE, R. Caracterização da composição florística e estrutura de uma Floresta Ombrófila Mista, no município de General Carneiro (PR). Ambiência, v. 1, n. 2., p. 229 - 237, 2005.

YARED, J. A. G. Efeitos de sistemas silviculturais na florística e na estrutura de florestas secundárias e primárias na Amazônia Oriental. 179 f. Tese (Doutorado em Ciências Florestais) Universidade Federal de Viçosa, Viçosa, 1996. 
